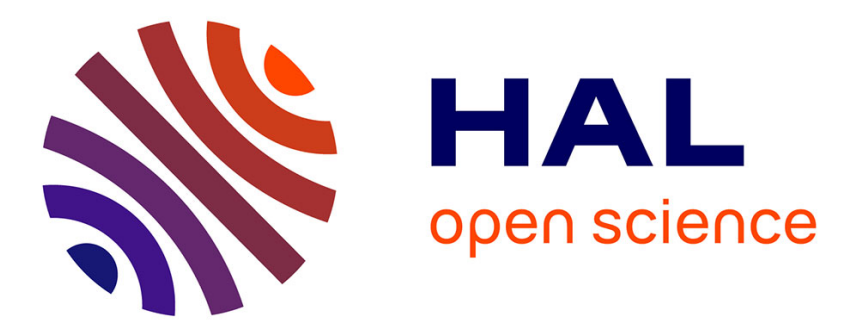

\title{
Different dominant transitions in holmium and ytterbium codoped oxyfluoride glass and glass ceramics originating from varying phonon energy environments
} Qunhuo Liu, Ying Tian, Caizhi Wang, Feifei Huang, Xufeng Jing, Junjie Zhang, Xianghua Zhang, Shiqing Xu

\section{To cite this version:}

Qunhuo Liu, Ying Tian, Caizhi Wang, Feifei Huang, Xufeng Jing, et al.. Different dominant transitions in holmium and ytterbium codoped oxyfluoride glass and glass ceramics originating from varying phonon energy environments. Physical Chemistry Chemical Physics, 2017, 19 (44), pp.29833-29839. 10.1039/c7cp06638d . hal-01671252

HAL Id: hal-01671252

https://hal-univ-rennes1.archives-ouvertes.fr/hal-01671252

Submitted on 24 Apr 2018

HAL is a multi-disciplinary open access archive for the deposit and dissemination of scientific research documents, whether they are published or not. The documents may come from teaching and research institutions in France or abroad, or from public or private research centers.
L'archive ouverte pluridisciplinaire HAL, est destinée au dépôt et à la diffusion de documents scientifiques de niveau recherche, publiés ou non, émanant des établissements d'enseignement et de recherche français ou étrangers, des laboratoires publics ou privés. 
Different dominant transitions in holmium and ytterbium codoped oxyfluoride glass and glass ceramic originated from varying phonon energy environments

Qunhuo Liu ${ }^{\mathrm{a}}$, Ying Tian ${ }^{\mathrm{a}, *}$, Caizhi Wang ${ }^{\mathrm{a}}$, Feifei Huang ${ }^{\mathrm{a}}$, Xufeng Jing ${ }^{\mathrm{b}}$, Junjie Zhang ${ }^{\mathrm{a}}$, Xianghua

\author{
Zhang $^{\mathrm{c}}$, Shiqing $\mathrm{Xu}^{\mathrm{a}, *}$ \\ ${ }^{a}$ College of Materials Science and Engineering, China Jiliang University, Hangzhou 310018, PR China
}

${ }^{b}$ Institute of Optoelectronic Technology, China Jiliang University, Hangzhou 310018, PR China

${ }^{c}$ Laboratory of Glasses and Ceramics, Institute of Chemical Science UMR CNRS 6226, University of Rennes 1, 35042 Rennes, France

Abstract: Transparent oxyfluoride glass and glass ceramic doped with $0.5 \% \mathrm{Ho}^{3+}$ and $1.0 \% \mathrm{Yb}^{3+}$ ions have been prepared. X-ray diffraction and transmission electron microscopy demonstrated the formation of $\mathrm{NaYF}_{4}$ nanocrystals during heat treatment process. Raman spectra indicated the variation of glass structure brought about by the formation of $\mathrm{NaYF}_{4}$ nanocrystals. XRD curves and Judd-Ofelt intensity parameters confirmed the incorporation of $\mathrm{Ho}^{3+}$ into $\mathrm{NaYF}_{4}$ nanocrystals. Significantly enhanced visible upconversion and $2.85 \mu \mathrm{m}$ emissions were achieved in glass ceramic under a $980 \mathrm{~nm}$ laser diode pumping. A broadband spectrum with a full-width at halfmaximum close to $132 \mathrm{~nm}$ was obtained in the glass ceramic. Besides, the calculated peak emission cross section is $0.6 \times 10^{-20} \mathrm{~cm}^{2}$, suggesting the glass ceramic is a promising gain material that can be applied to broadband amplifiers in mid-infrared region. Furthermore, energy transfer mechanisms in glass and glass ceramic were proposed based on visible to mid-infrared emission spectra. It was found that the change of photon energy environment around rare earth ions induced different dominant transitions in glass and glass ceramic. Finally, the influence of phonon energy on transition processes was further quantitatively investigated, which may provide useful guidance for obtaining highly efficient $2.85 \mu \mathrm{m}$ emission of holmium.

Graphical abstract:

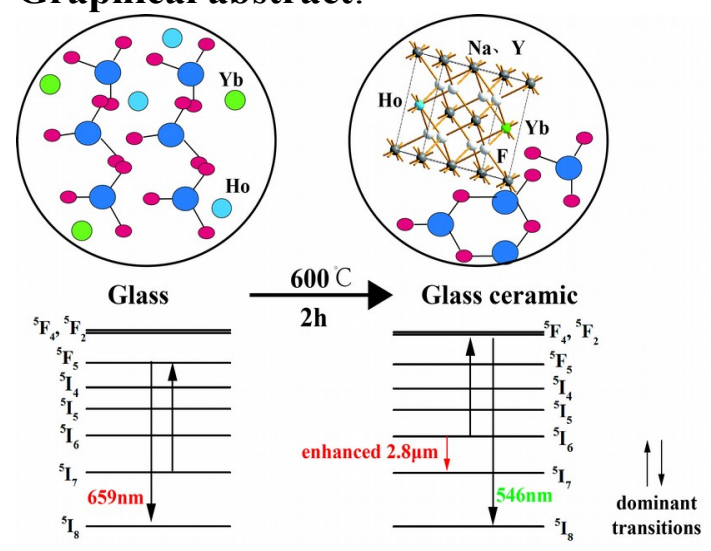

Key words: glass and glass ceramic; upconversion and $2.85 \mu \mathrm{m}$ emissions; phonon energy; energy transfer

\title{
1. Introduction
}

\footnotetext{
* $^{*}$ Corresponding author.Tel.: +86 571 86835781; fax: +86 571 28889527E-mail address:tianyingcjlu@163.com (Y. Tian), sxucjlu@163.com (S. Xu)
} 
Mid-infrared lasers operating around $3 \mu \mathrm{m}$ region are of particular interests not only_for military, medical and dental applications but also for scientific research, since $3 \mu \mathrm{m}$ laser source can be used as efficient laser pump sources for longer-wavelength laser oscillators ${ }^{1-5}$. Compared with other kinds of lasers, rare earth doped fiber laser has shown better performance due to its compact and flexible configuration, excellent beam quality and power scalability ${ }^{3,6}$.

The lasing wavelength is determined by the fluorescence transitions of the rareearth cation doped into the host materials. For around $3 \mu \mathrm{m}$ lasers, it can be acquired by the transition ${ }^{4} \mathrm{I}_{11 / 2} \rightarrow{ }^{4} \mathrm{I}_{13 / 2}$ of $\mathrm{Er}^{3+}(2.75 \mu \mathrm{m})$, the transition ${ }^{5} \mathrm{I}_{6} \rightarrow{ }^{5} \mathrm{I}_{7}$ of $\mathrm{Ho}^{3+}(2.85 \mu \mathrm{m})$ or the transition ${ }^{6} \mathrm{H}_{13 / 2} \rightarrow{ }^{6} \mathrm{H}_{15 / 2}$ of $\mathrm{Dy}^{3+}(2.9 \mu \mathrm{m})$. Unfortunately, the low output power $(0.1 \mathrm{~W})$ of $\mathrm{Dy}^{3+}$ doped ZBLAN fiber has restrained its further application ${ }^{2}$. Compared with $\mathrm{Er}^{3+}, \mathrm{Ho}^{3+}$ has shown the advantages of high efficiency ${ }^{7}$, high power $^{8}$ and broad tunability ${ }^{9}$. Due to the lack of readily commercialized laser diodes (LD) corresponding to the intrinsic absorption of $\mathrm{Ho}^{3+}$ ions, obtaining efficient $2.85 \mu \mathrm{m}$ laser has necessitated the use of other sensitizers ${ }^{1,9,10}$ such as $\mathrm{Pr}^{3+}, \mathrm{Er}^{3+}$ and $\mathrm{Yb}^{3+}$. Among them, the large absorption cross section ${ }^{11}$, long emission lifetime and simple electronic level structure of $\mathrm{Yb}^{3+}$ have made it as an appropriate and compelling sensitizer for transferring pumped energy to $\mathrm{Ho}^{3+}$.

A number of alternative glasses such as germanate ${ }^{12,}{ }^{13}$, tellurite $^{14}$, silicategermanate $^{15}$ and fluoride glasses ${ }^{2}$, have been researched as suitable host materials for mid-infrared lasers. Among these glass materials mentioned above, the practicality of tellurite and germanate glasses is limited by their high cost and insufficiently low concentration of $\mathrm{OH}^{-}$in the glasses. Despite various rare earth doped ZBLAN fiber lasers have been demonstrated good emission performances in $3 \mu \mathrm{m}$, ZBLAN fiber is fragile and has low damage threshold together with short useful length ${ }^{3}$. Silicate glasses, which are characterized by inexpensive manufacturing cost and excellent thermal stability, remain the most successful fiber host materials in acquired $1 \sim 2.2 \mu \mathrm{m}$ lasers $^{16-18}$. However, large maximum phonon energies of silicate glasses set an upper limit on the emission wavelength and induce multiphonon assisted non-radiative decay, which is mainly responsible for unsatisfied emission efficiency ${ }^{16}$. Even oxyfluoride silicate glass, which is a kind of silicate glass with the incorporation fluoride, could not solve this problem effectively ${ }^{19}$. Fortunately, transparent oxyfluoride silicate glass ceramics are capable of well solving this intrinsic difficulty attributed to embedded fluoride nanocrystals, which have superb fluorescent emission efficiency in mid-infrared region owing to its low phonon energies ${ }^{20,21}$. It has been reported that efficient $2.85 \mu \mathrm{m}$ emission was observed in glass ceramic containing $\mathrm{PbF}_{2}$ nanocrystals ${ }^{22}$, however, it is not satisfied with requirements of environmental protection. Our group has demonstrated that the efficient upconversion and $2.7 \mu \mathrm{m}$ emissions of $\mathrm{Er}^{3+}$ can be achieved in glass-ceramic containing $\mathrm{NaYF}_{4}$ nanocrystals ${ }^{23}$, thus a 2.85 emission of $\mathrm{Ho}^{3+}$ is also believed to be efficient in this kind of glass ceramic.

Our work is dedicated to two important and urgent problems facing rare earth doped glass ceramics. To date, enormous attention has been paying to the upconversion and around $2 \mu \mathrm{m}$ emissions in $\mathrm{Ho}^{3+} / \mathrm{Yb}^{3+}$ co-doped glass ceramic ${ }^{24,}{ }^{25}$. 
However, to our best knowledge, there are few results focusing on the $3 \mu \mathrm{m}$ emissions and it is very necessary to develop new $3 \mu \mathrm{m}$ laser gain materials. In addition, from glass to glass ceramic, the change of crystal field environment around rare earth ions induces different dominant transitions since various transitions are inherently linked. However, few reports take sufficient emissions into consideration when analyzing energy transfer process to achieve an efficient $3 \mu \mathrm{m}$ emission. Therefore, a detailed investigation of the different energy transfer mechanisms in glass and glass ceramic can be useful for the fluorescence enhancement in $3 \mu \mathrm{m}$ emission and the final desired applications.

In this work, we prepared $\mathrm{Ho}^{3+} / \mathrm{Yb}^{3+}$ co-doped oxyfluoride glass and glass ceramic with $\mathrm{NaYF}_{4}$ nanocrystals. The $2.85 \mu \mathrm{m}$ emission in $\mathrm{Ho}^{3+} / \mathrm{Yb}^{3+}$ co-doped oxyfluoride silicate glass ceramic with the nanocrystalline phase of $\mathrm{NaYF}_{4}$ was firstly reported. Based on measured fluorescence spectra (visible region, $1.2 \mu \mathrm{m}, 2 \mu \mathrm{m}$ and $2.85 \mu \mathrm{m}$ ) of $\mathrm{Ho}^{3+}$, we discussed energy transfer mechanisms and quantitatively estimated energy transfer efficiency in glass and glass ceramic.

\section{Experiment}

The glass and glass ceramic without rare earth doping were prepared to investigate the thermal and morphological characteristics as well as the glass structure. The $\mathrm{Ho} / \mathrm{Yb}$ codoped glass and glass ceramic were prepared to study the spectroscopic properties and the transition behavior of $\mathrm{Ho}^{3+}$ and $\mathrm{Yb}^{3+}$ ions. The precursor glass materials have the following moral composition: $40 \mathrm{SiO}_{2}-25 \mathrm{Al}_{2} \mathrm{O}_{3}-15 \mathrm{Na}_{2} \mathrm{CO}_{3}-10 \mathrm{NaF}-$ $10 \mathrm{YF}_{3}-2 \mathrm{x} \mathrm{Yb}_{2} \mathrm{O}_{3}-\mathrm{x} \mathrm{Ho}_{2} \mathrm{O}_{3}(\mathrm{x}=0,0.25)$, the samples are denoted as $\mathrm{G} 0, \mathrm{G}, \mathrm{GC} 0$ and $\mathrm{GC}$, for the glass and glass ceramic, respectively. The raw materials, which were analytically pure (99.99\% purity or higher), were mixed homogeneously and melted in a covered platinum crucible in a pit furnace at $1450^{\circ} \mathrm{C}$ for $30 \mathrm{~min}$. Then, the melts were quenched on preheated stainless steel plated before being annealed at $500 \circ \mathrm{C}$ for $2 \mathrm{~h}$ to release inner stress. Later the glass was cut into two pieces and one piece of glass was put into an oven at $600 \circ \mathrm{C}$ for heat treatment. Finally, the glass and the glass ceramic were cut and polished into the glass samples with thickness of $1 \mathrm{~mm}$ for optical and spectroscopic properties measurements.

Differential scanning calorimeter (DSC) was collected by NETZSCH DTA 404 PC at heating rate of $10 \mathrm{~K} / \mathrm{min}$. X-ray powder diffraction (XRD) patterns were recorded on a Rigaku D/max 2550 diffractometer with $\mathrm{Cu}-\mathrm{K} \alpha 1$ as the incident radiation source. Raman spectra were measured by a Raman spectrometer from Renishaw (inVia, UK) excited by 532nm laser. The micrographs of prepared glass ceramic were measured by transmission electron microscope (TEM, FEI TF20). Absorption spectrum was recorded by means of a PerkinElmer Lambda 900UV-vis-NIR spectrophotometer in the range of 350-2200 $\mathrm{nm}$ with a resolution of $1 \mathrm{~nm}$. Fluorescence spectra (1700-2300 $\mathrm{nm}$ and 2600-3200 nm) had been measured with a computer-controlled Triax 320 type spectrometer and detected with a liquid-nitrogen-cooled $\mathrm{PbS}$ detector upon excitation 
by $980 \mathrm{~nm}$ LD. All the measures were taken at room temperature and other conditions were kept as same as possible.

\section{Results and Discussions}

\subsection{Thermal and morphological characteristics}

Fig. 1 presents the DSC curve of G0, by which the characteristic temperatures were determined. The weak exothermal peak at $622^{\circ} \mathrm{C}$ is caused by the crystallization of fluoride crystals of the glass matrix, while the strong exothermal peak at $728^{\circ} \mathrm{C}$ can be attributed to the crystallization of silicate oxides of the glass matrix. The heat treatment temperature was chosen to moderate $600^{\circ} \mathrm{C}$ in order to remain the sample transparent and the crystal phase stable. The values of $\mathrm{T}_{\mathrm{g}}$ and $\mathrm{T}_{\mathrm{x} 2}$ are $529^{\circ} \mathrm{C}$ and $669^{\circ} \mathrm{C}$, respectively. The large $\Delta \mathrm{T}\left(\Delta \mathrm{T}=\mathrm{T}_{\mathrm{x} 2}-\mathrm{T}_{\mathrm{g}}=140^{\circ} \mathrm{C}\right)$ of the glass suggests that it has a good thermal stability, which is favorable for the fiber drawing.

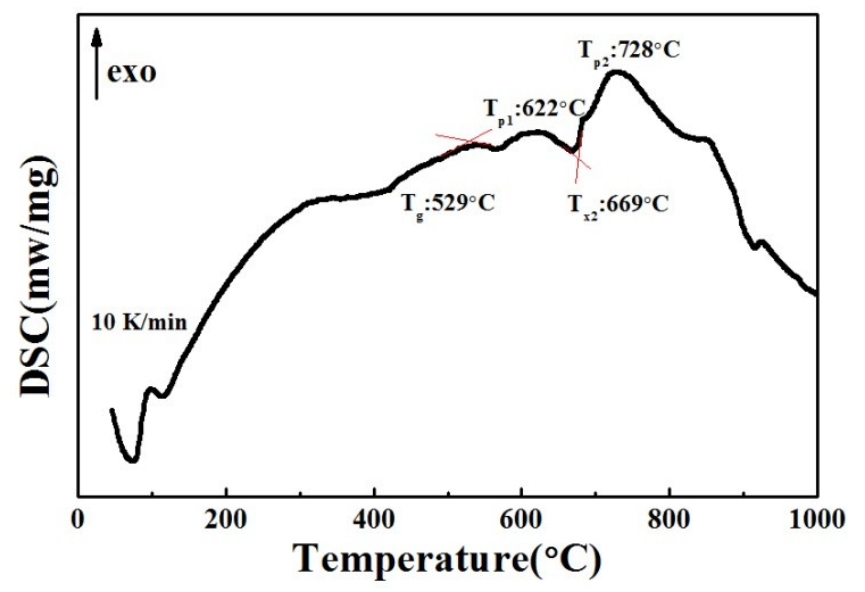

Figure 1 DSC curve of oxyfluoride silicate glass host.

Fig. 2 shows the XRD patterns for the glass and glass ceramics. There are no crystalline peaks in the XRD curve of the precursor glass due to its amorphous structure. However, obvious diffraction peak signals ascribed to $\mathrm{NaYF}_{4}$ (PDF\#060342) are observed in the XRD curve of the glass ceramics, confirming the formation of $\mathrm{NaYF}_{4}$ nanoparticles within the glass matrix during the heat treatment. $\mathrm{Ho}^{3+}$ or $\mathrm{Yb}^{3+}$ ions tend to occupy the cationic sites $\left(\mathrm{Y}^{3+}\right)$ in the $\mathrm{NaYF}_{4}$ nanocrystals due to their size and charge similarity. It can be seen that the peak position is slightly shifted to the right from $\mathrm{GC} 0$ to $\mathrm{GC}$, owing to partial substitution of $\mathrm{Y}^{3+}$ (ionic radius $0.09 \mathrm{~nm}$ ) cations by $\mathrm{Yb}^{3+}$ (ionic radius $0.0868 \mathrm{~nm}$ ) ions leading to lattice contraction. Therefore, the shift of peak position indicates that the rare earth ions enter into $\mathrm{NaYF}_{4}$ nanocrystals. Besides, in the $\mathrm{Yb} / \mathrm{Ho}$ codoped glass system, if the concentration of rare earth ions is too small, the absorption coefficient at around $980 \mathrm{~nm}$ would be greatly reduced, resulting in lower emission intensity at $2.85 \mu \mathrm{m}$. On the contrary, if the concentration of rare earth ions is too large, the formation of $\mathrm{NaYF}_{4}$ nanocrystals was suppressed, which was reflected in the diffraction peak intensities of GC0 and G0 samples. So a middle-ground approach was taken in our experiment, the concentration of $\mathrm{Yb}^{3+}$ and $\mathrm{Ho}^{3+}$ ions were $1.0 \mathrm{~mol} \%$ and $0.5 \mathrm{~mol} \%$, respectively. 
TEM analysis of GC0 sample was carried out to obtain size, morphology and direct imaging of $\mathrm{NaYF}_{4}$ nanocrystals. The $15-35 \mathrm{~nm}$ sized and spherical crystallites in the TEM picture correspond to $\mathrm{NaYF}_{4}$ nanocrystals, as shown in Fig. 2(b), are homogenously distributed in the glass matrix. Clear lattice fringes of HRTEM image in Fig. 2(c) indicates the high crystallinity of $\mathrm{NaYF}_{4}$ nanocrystals.
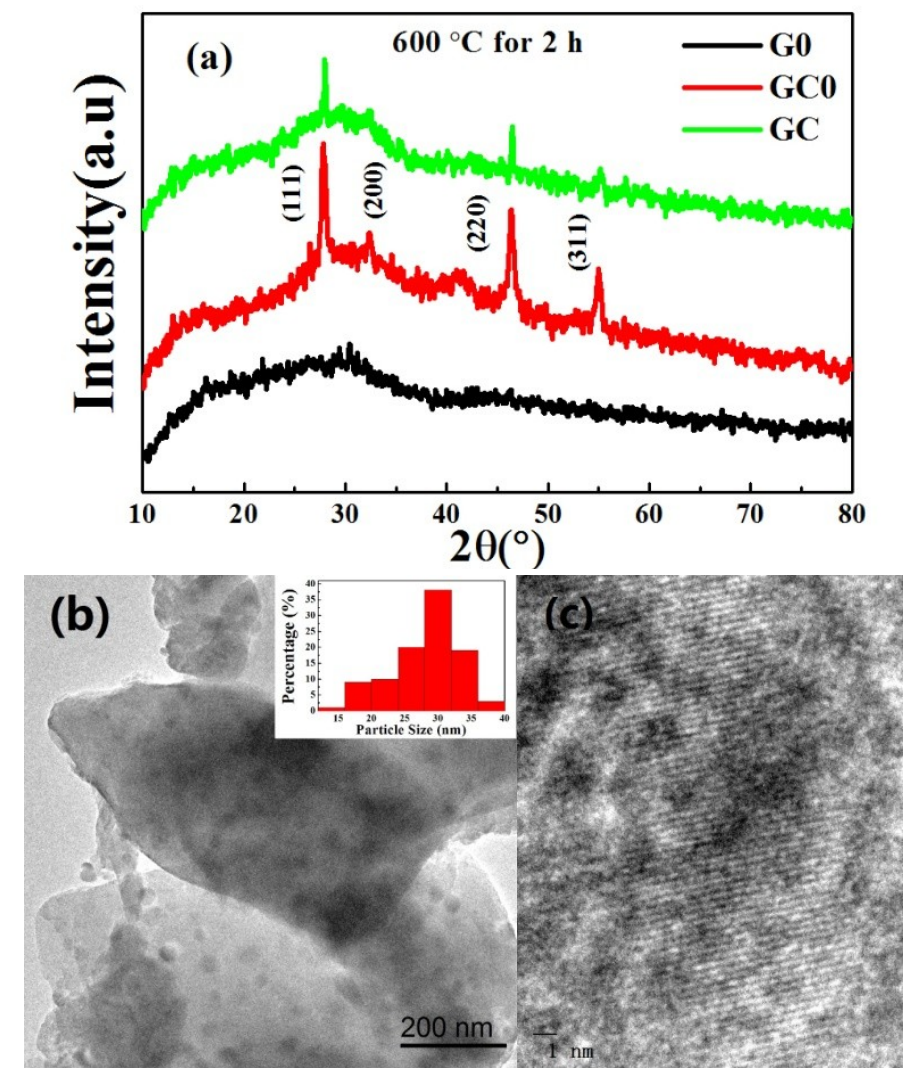

Figure 2 (a) presents the XRD pattern of glass and glass ceramics. (b) and (c) present the TEM and HRTEM picture of GC0 sample, respectively. The inset of (b) is the size distribution histogram of GC0 sample.

\subsection{Raman spectra}

The raman spectra of G0 and GC0 are shown in Fig. 3. A high-frequency band at 900-1200 $\mathrm{cm}^{-1}$ corresponding to Si-O-Si asymmetric stretching vibration, a weak peak at $794 \mathrm{~cm}^{-1}$ caused by Si-O-Si bend vibration and a mid-frequency band at 300-600 $\mathrm{cm}^{-1}$ associated to Si-O-Si symmetric stretching vibration can be observed in the glass and glass ceramic ${ }^{26}$. However, four sharp peaks were emerged in the spectrum of the glass ceramic when compared with that of the glass. It was reported that the peak at the low-frequency region can be attributed to the vibration of cation-fluorine bond ${ }^{27}$, thus the peak at $244 \mathrm{~cm}^{-1}$ and $324 \mathrm{~cm}^{-1}$ should be ascribed to the vibration of $\mathrm{Na}-\mathrm{F}$ bond and Y-F bond in $\mathrm{NaYF}_{4}$ nanocrystals. Other studies ${ }^{28,29}$ have uncovered similar results in vibrational modes of $\mathrm{NaYF}_{4}$ nanocrystals. In addition, the peak at $425 \mathrm{~cm}^{-1}$, $493 \mathrm{~cm}^{-1}$ and $592 \mathrm{~cm}^{-1}$, which are very weak and generally difficult to detect in silicate glass, were observed in this glass ceramic. The peak at $425 \mathrm{~cm}^{-1}$ is assigned to a symmetric ring-breathing mode involving mainly oxygen motion, whereas the peak at 
$493 \mathrm{~cm}^{-1}$ and $592 \mathrm{~cm}^{-1}$ are related respectively to the symmetric stretch of planar threefold and fourfold ring structures ${ }^{30}$. Therefore, the broken glass network due to the formation of $\mathrm{NaYF}_{4}$ nanocrystals are connected thorough linking $\mathrm{SiO}_{4}$ tetrahedra to form various-membered interconnected rings ${ }^{31}$.

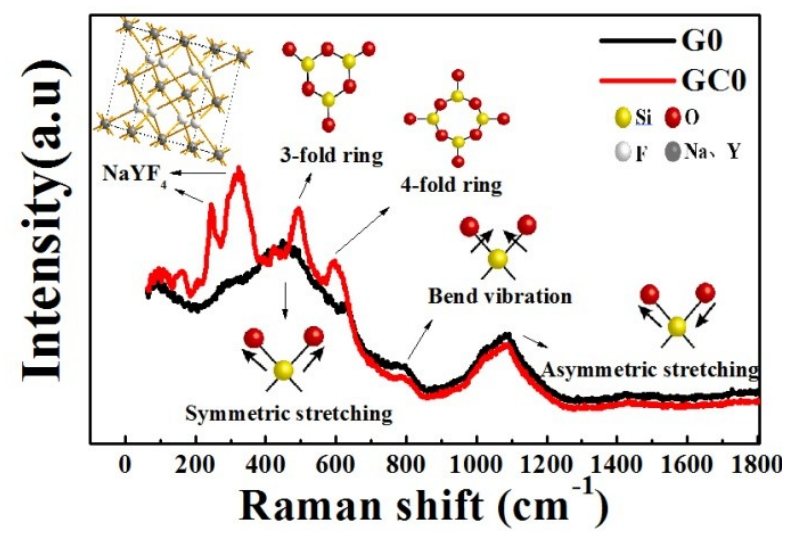

Figure 3 Raman spectra of glass and glass ceramic, inset indicates vibration modes corresponding to the raman vibration peaks.

\subsection{Absorption spectra and Judd-Ofelt analysis}

Fig. 4 indicates the absorption spectra of $\mathrm{G}$ and $\mathrm{GC}$ in the range of 350-2200nm at room temperature, and some absorption bands of $\mathrm{Ho}^{3+}$ corresponding to the $4 \mathrm{f}^{12}-4 \mathrm{f}^{12}$ intra-configurational electronic transitions from the ground state ${ }^{5} \mathrm{I}_{8}$ to the higher exited states are labeled. The strong absorption of $\mathrm{Yb}^{3+}$ at $980 \mathrm{~nm}$ suggests that $\mathrm{G}$ and GC can be effectively pumped by readily available commercial $980 \mathrm{~nm}$ laser diodes. It is noted that compared to that of $\mathrm{G}$, the ultraviolet absorption cut-off wavelength of GC shows a red shift, which is due to light scattering (Rayleigh scattering) of nanocrystals in $\mathrm{GC}^{25,32}$. Using the measured absorption spectra and Judd-Ofelt_(J-O) theory ${ }^{33,}{ }^{34}$, the J-O parameters $\Omega_{\mathrm{t}}\left(\Omega_{2}, \Omega_{4}\right.$ and $\left.\Omega_{6}\right)$ were determined through leastsquare fit and were listed in inset of Fig. 4. For the calculation of J-O parameters, the density of the glass and glass ceramic was measured as $2.857 \mathrm{~g} / \mathrm{cm}^{2}$ and $2.851 \mathrm{~g} / \mathrm{cm}^{2}$, respectively. According to the theory, $\Omega_{2}$ is strongly dependent on the local environments of rare earth ions sites, and it decreases with the rare earth ions enter from oxide glass matrix into fluoride crystal environment which has better symmetry and weaker covalency ${ }^{35}$. The $\Omega_{2}$ of GC is smaller than that of $\mathrm{G}$, confirming the incorporation of $\mathrm{Ho}^{3+}$ into $\mathrm{NaYF}_{4}$ nanoparticles. 


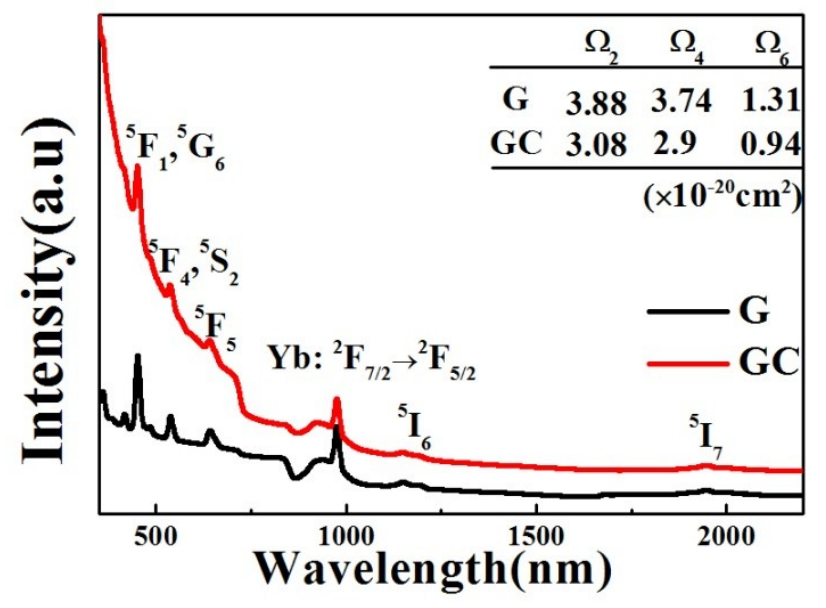

Figure 4 Absorption spectra of G and GC samples. The inset lists the Judd-Ofelt parameters of $\mathrm{Ho}^{3+}$ in $\mathrm{G}$ and $\mathrm{GC}$ samples.

\subsection{Emission spectra and emission cross section}

As is clearly seen in the Fig. 5(a), there are three visible upconversion emission bands, whose peaks are located at $546 \mathrm{~nm}, 659 \mathrm{~nm}$ and $752 \mathrm{~nm}$ corresponding to $\mathrm{Ho}^{3+}$ : ${ }^{5} \mathrm{~S}_{2},{ }^{5} \mathrm{~F}_{4} \rightarrow{ }^{5} \mathrm{I}_{8},{ }^{5} \mathrm{~S}_{2} \rightarrow{ }^{5} \mathrm{I}_{8}$ and ${ }^{5} \mathrm{~S}_{2},{ }^{5} \mathrm{~F}_{4} \rightarrow{ }^{5} \mathrm{I}_{7}$ transitions. Due to significant enhancement of upconversion emission in glass ceramic, glass ceramic presents green but glass appears red under $980 \mathrm{~nm}$ LD pump, which can be observed by naked eyes. The 1.2 $\mu \mathrm{m}$ emission spectra of $\mathrm{G}$ and GC are illustrated in Fig. 5(b). Apparent enhancement of $1.2 \mu \mathrm{m}$ emission was also observed in glass ceramic. Besides, a small peak at 1150 $\mathrm{nm}$ was observed in GC, which may be caused by the energy level splitting of ${ }^{5} \mathrm{I}_{6}$ level in the crystal field. The $2 \mu \mathrm{m}$ emission intensity of glass ceramic was slightly decreased compared with that of glass, as shown in Fig. 5(c). Fig. 5(d) shows a great enhancement of $2.85 \mu \mathrm{m}$ emission of $\mathrm{Ho}^{3+}$ in $\mathrm{GC}$ compared with that in G. Besides, the full-width at half-maximum (FWHM) is close to $132 \mathrm{~nm}$ at $2.85 \mu \mathrm{m}$ emission.
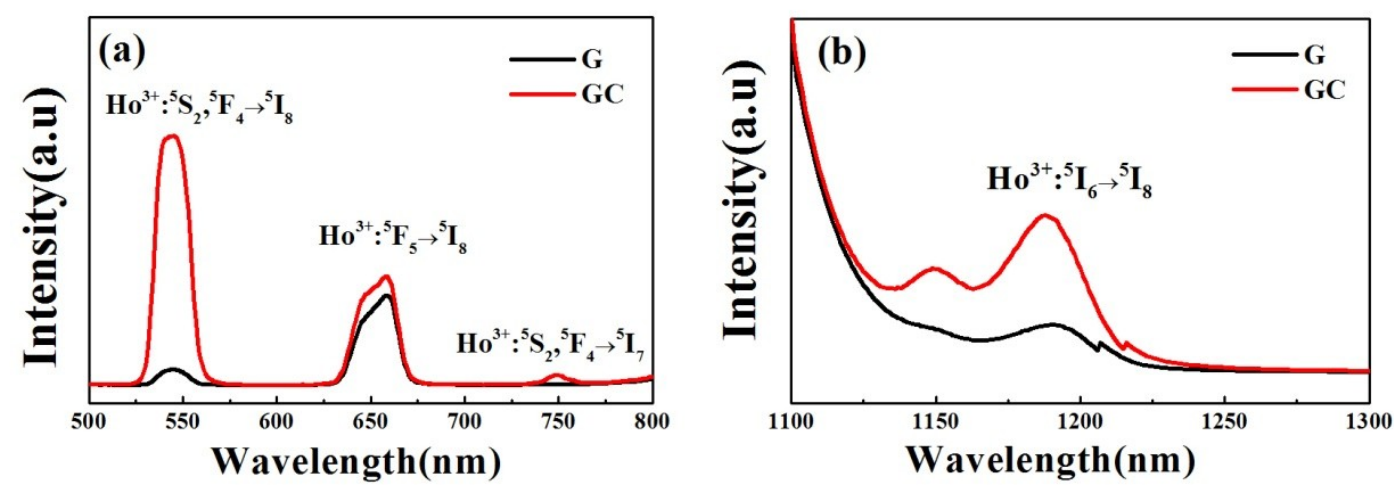

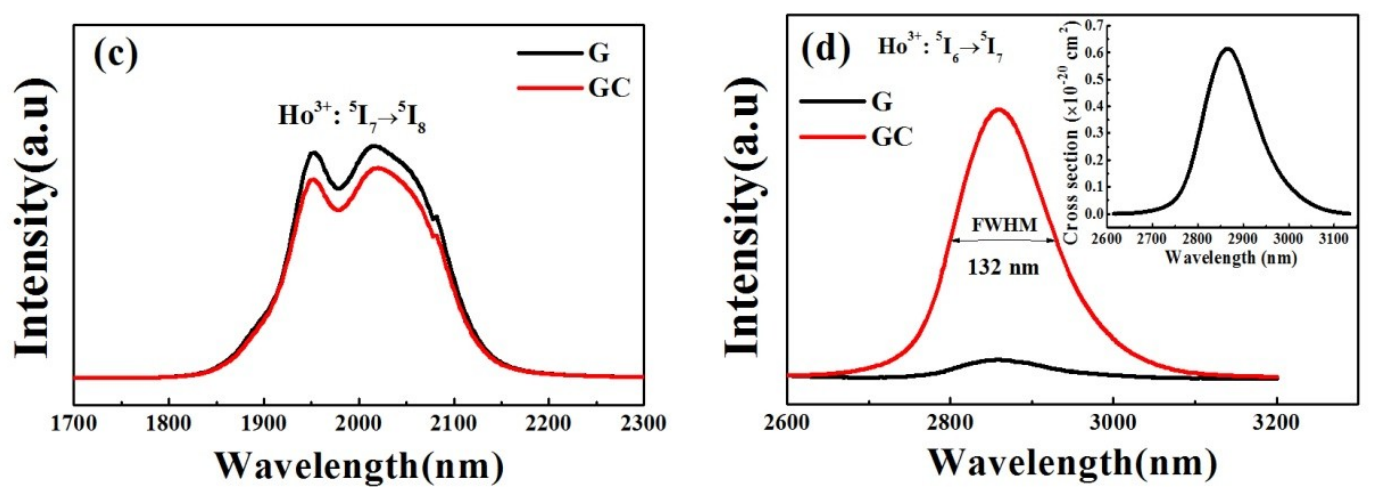

Figure 5 (a) shows the visible upconversion emission spectra, (b) shows the $1.2 \mu \mathrm{m}$ emission spectra, (c) shows the $2 \mu \mathrm{m}$ emission spectra and (d) shows the $2.85 \mu \mathrm{m}$ emission spectra of glass and glass ceramic. The inset of (d) is the corresponding emission cross section of $\mathrm{Ho}^{3+}$ in glass ceramic.

The emission cross section is an important criterion for evaluating the quality of laser gain materials. The $2.85 \mu \mathrm{m}$ emission cross section is subsequently calculated by the Füchtbauer -Ladenburg equation ${ }^{36}$ :

$$
\sigma_{e m}(\lambda)=\frac{\lambda^{5} A_{r a d}}{8 \pi c n^{2}} \frac{I(\lambda)}{\int \lambda I(\lambda) d \lambda}
$$

where $\lambda$ is the wavelength, $I(\lambda)$ is the fluorescence intensity, $I(\lambda) / \int \lambda I(\lambda) d \lambda$ is the normalized line shape function of the experimental emission spectrum, $A_{\text {rad }}$ is the radiative transition probability, $\mathrm{c}$ and $\mathrm{n}$ are the light speed and the index of refraction(here the value is 1.54 ), respectively.

The calculated peak emission cross section at $2.85 \mu \mathrm{m}$ is $0.6 \times 10^{-20} \mathrm{~cm}^{2}$, which is larger than that of GGG crystal $\left(0.3 \times 10^{-20} \mathrm{~cm}^{2}\right)^{37}$ and ZBLAN glass $\left(0.5 \times 10^{-20} \mathrm{~cm}^{2}\right)^{38}$ but smaller than that of fluorotellurite glass $\left(1.51 \times 10^{-20} \mathrm{~cm}^{2}\right)^{39}$ and $\mathrm{Ge}_{20} \mathrm{Ga}_{5} \mathrm{Sb}_{10} \mathrm{~S}_{65}$ glass $\left(1.67 \times 10^{-20} \mathrm{~cm}^{2}\right)^{40}$. The large emission cross sections of latter two glasses can be ascribed to their high refractive index. Considering the broadband spectrum of GC, this kind of glass ceramic is predicted to be a promising gain material that can be applied to broadband amplifiers in mid-infrared region.

\subsection{Energy transfer}

The energy level diagrams of $\mathrm{Ho}^{3+}$ and $\mathrm{Yb}^{3+}$ and energy transfer mechanism from $\mathrm{Yb}^{3+}$ to $\mathrm{Ho}^{3+}$ are depicted in Fig. 6.

(1)The ions in the $\mathrm{Yb}^{3+}:{ }^{2} \mathrm{~F}_{7 / 2}$ level are pumped to the ${ }^{2} \mathrm{~F}_{5 / 2}$ level via ground state absorption (GSA: $\mathrm{Yb}^{3+}:{ }^{2} \mathrm{~F}_{7 / 2}+$ a phonon $\rightarrow{ }^{2} \mathrm{~F}_{5 / 2}$ ) when excited by commercial $980 \mathrm{~nm}$ LD.

(2)Subsequently, $\mathrm{Yb}^{3+}:{ }^{2} \mathrm{~F}_{5 / 2}$ transfer its energy to the $\mathrm{Ho}^{3+}:{ }^{5} \mathrm{I}_{6}$ levels via an ET1 $\left(\mathrm{Yb}^{3+}:{ }^{2} \mathrm{~F}_{5 / 2}+\mathrm{Ho}^{3+}:{ }^{5} \mathrm{I}_{8} \rightarrow \mathrm{Yb}^{3+}:{ }^{2} \mathrm{~F}_{7 / 2}+\mathrm{Ho}^{3+}:{ }^{5} \mathrm{I}_{6}\right)$ process, owing to a small energy mismatch between them.

(3)On the one hand, the $\mathrm{Ho}^{3+}$ ions in ${ }^{5} \mathrm{I}_{6}$ level can be populated to the higher ${ }^{5} \mathrm{~F}_{4}$ or ${ }^{5} \mathrm{~S}_{2}$ level by excited state absorption (ESA1: ${ }^{5} \mathrm{I}_{6}+$ a phonon $\rightarrow{ }^{5} \mathrm{~F}_{4}$ or ${ }^{5} \mathrm{~S}_{2}$ ) or energy 
transfer (ET2: $\mathrm{Yb}^{3+}:{ }^{2} \mathrm{~F}_{5 / 2}+\mathrm{Ho}^{3+}:{ }^{5} \mathrm{I}_{6} \rightarrow \mathrm{Yb}^{3+}:{ }^{2} \mathrm{~F}_{7 / 2}+\mathrm{Ho}^{3+}:{ }^{5} \mathrm{~F}_{4}$ or $\left.{ }^{5} \mathrm{~S}_{2}\right)$ process.

(4)Subsequently, the $\mathrm{Ho}^{3+}$ ions in ${ }^{5} \mathrm{~F}_{4}$ or ${ }^{5} \mathrm{~S}_{2}$ level radiate their energy transfer to metastable state $\left({ }^{5} \mathrm{I}_{7}\right)$ and ground state $\left({ }^{5} \mathrm{I}_{8}\right)$, generating 546 and $753 \mathrm{~nm}$ light emission $\left((4 \mathrm{a}):{ }^{5} \mathrm{~F}_{4}\left({ }^{5} \mathrm{~S}_{2}\right) \rightarrow{ }^{5} \mathrm{I}_{8}+546 \mathrm{~nm} ;(4 \mathrm{~b}):{ }^{5} \mathrm{~F}_{4}\left({ }^{5} \mathrm{~S}_{2}\right) \rightarrow{ }^{5} \mathrm{I}_{7}+753 \mathrm{~nm}\right)$.

(5)On the other hand, the $\mathrm{Ho}^{3+}$ ions in ${ }^{5} \mathrm{I}_{6}$ level can radiate their energy transfer to metastable state $\left({ }^{5} \mathrm{I}_{7}\right)$ and ground state $\left({ }^{5} \mathrm{I}_{8}\right)$, generating 2.85 and $1.2 \mu \mathrm{m}$ light emission ((5a) : $\left.{ }^{5} \mathrm{I}_{6} \rightarrow{ }^{5} \mathrm{I}_{7}+2.85 \mu \mathrm{m} ;(5 \mathrm{~b}):{ }^{5} \mathrm{I}_{5} \rightarrow{ }^{5} \mathrm{I}_{8}+1.2 \mu \mathrm{m}\right)$.

(6) The $\mathrm{Ho}^{3+}$ ions in ${ }^{5} \mathrm{I}_{7}$ level can be populated to the higher ${ }^{5} \mathrm{~F}_{5}$ level by excited state absorption (ESA2: ${ }^{5} \mathrm{I}_{7}+$ a phonon $\rightarrow{ }^{5} \mathrm{~F}_{5}$ ) or energy transfer $\left(\mathrm{ET} 3: \mathrm{Yb}^{3+}:{ }^{2} \mathrm{~F}_{5 / 2}+\mathrm{Ho}^{3+}\right.$ : $\left.{ }^{5} \mathrm{I}_{7} \rightarrow \mathrm{Yb}^{3+}:{ }^{2} \mathrm{~F}_{7 / 2}+\mathrm{Ho}^{3+}:{ }^{5} \mathrm{~F}_{5}\right)$ process.

(7)Subsequently, the $\mathrm{Ho}^{3+}$ ions in ${ }^{5} \mathrm{~F}_{5}$ level radiate their energy transfer to ground state $\left({ }^{5} \mathrm{I}_{8}\right)$, generating $657 \mathrm{~nm}$ light emission $\left({ }^{5} \mathrm{~F}_{5} \rightarrow{ }^{5} \mathrm{I}_{8}+657 \mathrm{~nm}\right)$.

(8)What's more, the ions in the ${ }^{5} \mathrm{I}_{7}$ level can also radiate their energy transfer to ground state $\left({ }^{5} \mathrm{I}_{8}\right)$, generating $2 \mu \mathrm{m}$ light emission $\left({ }^{5} \mathrm{I}_{7} \rightarrow{ }^{5} \mathrm{I}_{8}+2 \mu \mathrm{m}\right)$.

In the oxyfluoride silicate glass, $\mathrm{Ho}^{3+}$ ions are easily coupled to the non-bridging oxygen on the strong $\mathrm{O}-\mathrm{Si}$ or $\mathrm{O}-\mathrm{Al}$ bonds, which have high phonon energy $\left(1100 \mathrm{~cm}^{-}\right.$ $\left.{ }^{1}\right)$. The energy gap between ${ }^{5} \mathrm{I}_{6}$ and ${ }^{5} \mathrm{I}_{7}$ levels is about $2551 \mathrm{~cm}^{-1}$, nonradiatively relax is easy to occur with only two or three phonons assisted. Thus $\mathrm{Ho}^{3+}$ ions in ${ }^{5} \mathrm{I}_{6}$ level are easy to nonradiatively relax to ${ }^{5} \mathrm{I}_{7}$ level through multi-phonon assisted process, leading to weak $2.85 \mu \mathrm{m}$ emission in G. Therefore, (6) and (7) transition processes are dominant in the oxyfluoride silicate glass, which were demonstrated by the upconversion emission spectrum of $\mathrm{G}$.

In the glass ceramic, $\mathrm{Ho}^{3+}$ ions enter into fluoride nanocrystals, which have low phonon energy $\left(324 \mathrm{~cm}^{-1}\right)$. Multi-phonon assisted nonradiatively relax rate is greatly decreased, causing enhanced $1.2 \mu \mathrm{m}$ emission and significant enhancement of 2.85 $\mu \mathrm{m}$ emission in GC. Accordingly, (3) and (4) transition processes are dominant in the glass ceramic, which were proved by the upconversion emission spectrum of GC. The $\mathrm{Ho}^{3+}$ ions at ${ }^{5} \mathrm{I}_{7}$ level are decreased with more $\mathrm{Ho}^{3+}$ ions participate in (3) transition process, resulting in the decrease of $\mathrm{Ho}^{3+}$ ions performing (8) transition process, which was confirmed by the slightly reduced $2 \mu \mathrm{m}$ emission in GC sample.

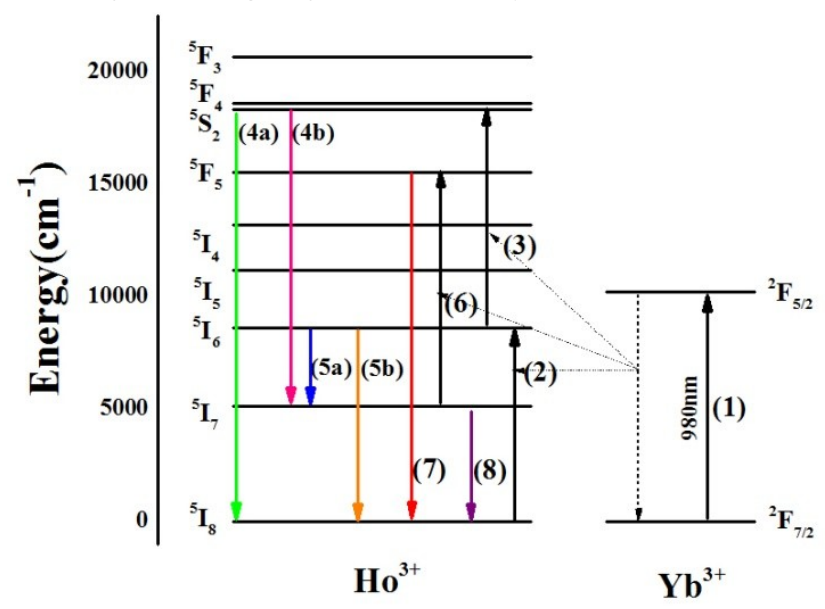

Figure 6 Energy level diagrams and energy transfer mechanism from $\mathrm{Yb}^{3+}$ to $\mathrm{Ho}^{3+}$.

The fluoride nanocrystals provide a low-phonon-energy environment for $\mathrm{Ho}^{3+}$ ions, 
which can effectively restrict the multi-phonon relaxation of excited levels and thus enhance upconversion and mid-infrared emissions. However, it may also limit the energy transfer probability of $\mathrm{Yb}^{3+}$ ions to $\mathrm{Ho}^{3+}$ ions in case of non-resonant energy transfer processes, which are generally governed by emission or annihilation of host phonons ${ }^{28}$. Hence, it is necessary to quantitatively investigate the energy transfer process further, which can be evaluated by the calculations of the absorption and emission cross sections of $\mathrm{Yb}^{3+}$ and $\mathrm{Ho}^{3+}$ ions using Dexter's theory. For a dipoledipole interaction, the microscopic transfer probabilities between rare-earth ions can be expressed $\mathrm{as}^{41}$ :

$$
W_{D-A}(R)=\frac{C_{D-A}}{R^{6}}
$$

where $\mathrm{D}$ and $\mathrm{A}$ represents the donor ions and the acceptor ions, respectively. $\mathrm{R}$ is the distance between them. The energy transfer constant can be expressed $\mathrm{C}_{\mathrm{D}-\mathrm{A}}$, which is shown as follows ${ }^{41}$ :

$$
C_{D-A}=\frac{R_{C}^{6}}{\tau_{D}}
$$

In this formula, $R_{C}$ is the relative radius of the interaction, $\tau_{D}$ is the intrinsic lifetime. When considering phonon participation, the energy transfer coefficient $\left(\mathrm{C}_{\mathrm{D}-}\right.$ A) can be determined by the following equation ${ }^{41}$ :

$$
\begin{gathered}
\mid i^{A \mid}(\lambda) d \lambda \\
C_{D-A}^{+i}=\frac{6 c g_{\text {low }}^{D} \sigma_{i}}{(2 \pi)^{4} n^{2} g_{\text {up }}^{D}} \sum_{m=0}^{\infty} e^{-(2 \dot{n}+1) S_{0}} \frac{S_{0}^{m}}{m !}(\dot{n}+1)^{m} \int \sigma_{\text {ems }}^{D} \dot{i}
\end{gathered}
$$

where $\mathrm{c}$ is the light speed, $\mathrm{n}$ is the refractive index, $g_{\text {low }}^{D}$ and $g_{\text {up }}^{D}$ are the degeneracy of the lower and upper levels of the donor, respectively. $\hbar \omega_{0}$ is the maximum phonon energy, $\dot{n}$ is the average occupancy, $m$ is the number of the phonons participating in the energy transfer, $S_{0}$ is the Huang-Rhys factor and $\begin{gathered}+i \\ \lambda_{m}^{i}\end{gathered}$ $=1 /\left(1 / \lambda-m \hbar \omega_{0}\right)$ is the wavelength with $\mathrm{m}$ phonon creation.

The refractive index of G and GC is 1.5415 and 1.5408, respectively. The phonon energy has been taken as $1100 \mathrm{~cm}^{-1}$ for oxyfluoride glass and $324 \mathrm{~cm}^{-1}$ for the fluoride nanocrystals, as determined by raman spectra. Based on the $\mathrm{J}-\mathrm{O}$ parameters of $\mathrm{Ho}^{3+}$ in $\mathrm{G}$ and $\mathrm{GC}$, the radiative transition probability of ${ }^{5} \mathrm{I}_{6} \rightarrow{ }^{5} \mathrm{I}_{8}$ process in $\mathrm{G}$ and $\mathrm{GC}$ is calculated to be $130.39 \mathrm{~s}^{-1}$ and $94.74 \mathrm{~s}^{-1}$, respectively. The absorption and emission cross sections of $\mathrm{Ho}^{3+}$ at $1.2 \mu \mathrm{m}$ and $\mathrm{Yb}^{3+}$ at $980 \mathrm{~nm}$ in $\mathrm{G}$ and $\mathrm{GC}$ were calculated by measured absorption spectra and emission spectra based on Füchtbauer-Ladenburg equation $^{36}$ and Beer-Lambert law ${ }^{42}$, as presented in Fig. 7. 

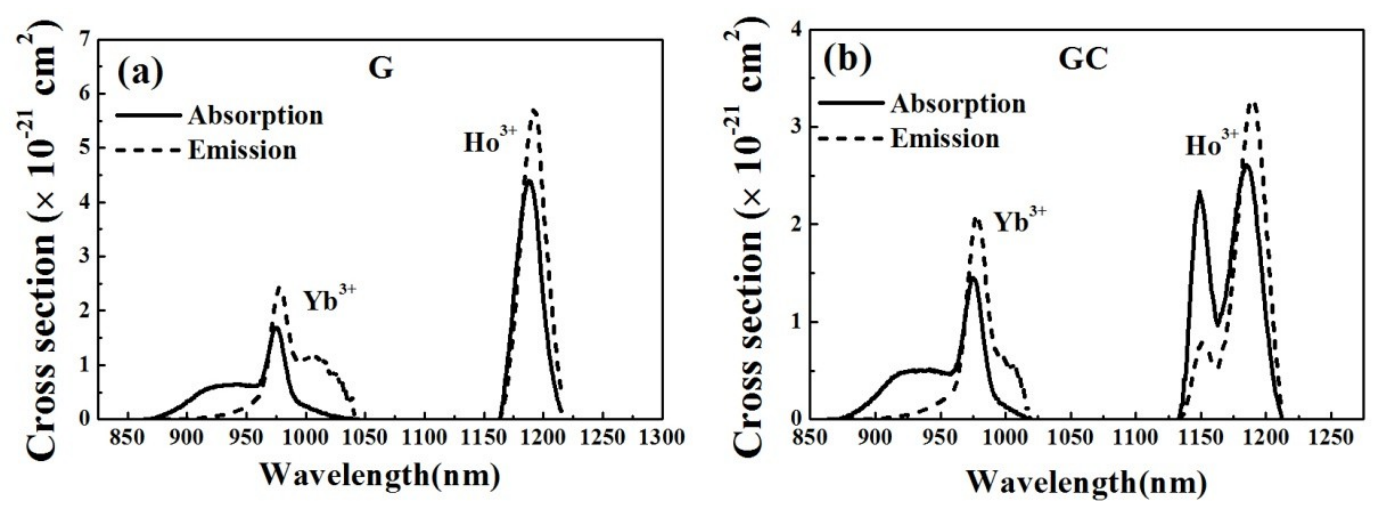

Figure 7 Absorption and emission cross sections of $\mathrm{Ho}^{3+}$ at $1.2 \mu \mathrm{m}$ and $\mathrm{Yb}^{3+}$ at $980 \mathrm{~nm}$ in the (a) oxyfluoride glass and (b) the glass ceramic.

Table 1 tabulated the energy transfer microscopic parameters and the number of phonons necessary to assist the energy transfer process in $\mathrm{Yb}^{3+} / \mathrm{Ho}^{3+}$ codoped glass and glass ceramic. One can find that hardly no phonons assistance for the energy transfer of $\mathrm{Yb}^{3+}:{ }^{2} \mathrm{~F}_{5 / 2} \rightarrow \mathrm{Yb}^{3+}:{ }^{2} \mathrm{~F}_{5 / 2}$ process in both $\mathrm{G}$ and GC. However, the proportion of zero phonon participate the energy transfer of $\mathrm{Yb}^{3+}:{ }^{2} \mathrm{~F}_{5 / 2} \rightarrow \mathrm{Ho}^{3+}:{ }^{5} \mathrm{I}_{6}$ process in $\mathrm{G}$ and GC is only $27.19 \%$ and $51.17 \%$, respectively. Furthermore, the energy transfer microparameters $\mathrm{C}_{\mathrm{DA}}$ of $\mathrm{Yb}^{3+}:{ }^{2} \mathrm{~F}_{5 / 2} \rightarrow \mathrm{Ho}^{3+}:{ }^{5} \mathrm{I}_{6}$ process in $\mathrm{GC}$ was $0.59 \times 10^{-41} \mathrm{~cm}^{6} / \mathrm{s}$, which was much smaller than that in $\mathrm{G}\left(16.94 \times 10^{-41} \mathrm{~cm}^{6} / \mathrm{s}\right)$. Therefore, the effect of low phonon energy in restricting the multi-phonon assisted nonradiative relaxation has a greater impact than the effect of low phonon energy in limiting energy transfer on the mid-infrared emission. The result that the silicate host contributes approximately several orders of magnitude more than that of the fluoride host was also found in $\mathrm{Nd}^{3+} \rightarrow \mathrm{Yb}^{3+}$ phonon assisted energy transfer process ${ }^{28}$. The significantly enhanced (3) transition process in fluoride nanocrystals, which was reflected by great enhancement in $546 \mathrm{~nm}$ on spectrum, was mainly responsible for this. Nevertheless, the energy transfer microparameters $\mathrm{C}_{\mathrm{DD}}$ of $\mathrm{Yb}^{3+}:{ }^{2} \mathrm{~F}_{5 / 2} \rightarrow \mathrm{Yb}^{3+}:{ }^{2} \mathrm{~F}_{5 / 2}$ process was not decreased so much. It indicated that the change of phonon energy environment has a greater impact on phonon-assisted non-resonant energy transfer process than on resonant energy transfer process. As the upconversion and mid-infrared emissions were both enhanced in a low phonon energy environment, the results suggest one can try to restrain (3) transition process to obtain high efficient $2.85 \mu \mathrm{m}$ emission of $\mathrm{Ho}^{3+}$.

Table 1 Energy transfer microparameters of $\mathrm{Yb}^{3+}$ and $\mathrm{Ho}^{3+}$ in glass and glass ceramic.

\begin{tabular}{|c|c|c|c|c|c|}
\hline \multirow{2}{*}{$\frac{\text { Energy transfer }}{\mathrm{Yb}^{3+}:{ }^{2} \mathrm{~F}_{5 / 2} \rightarrow \mathrm{Ho}^{3+}:{ }^{5} \mathrm{I}_{6}}$} & \multirow[b]{2}{*}{$\mathrm{G}$} & \multicolumn{3}{|c|}{$\mathrm{N}$ (phonons-assist) (\%) } & \multirow{2}{*}{$\frac{\mathrm{C}_{\mathrm{DA}(\mathrm{D})}\left(\times 10^{-41} \mathrm{~cm}^{6} / \mathrm{s}\right)}{16.94}$} \\
\hline & & $0(27.19)$ & $1(53.23)$ & $2(19.53$ & \\
\hline & $\mathrm{GC}$ & $0(51.17)$ & 1(31.14) & $\begin{array}{c})^{2}(10.97\end{array}$ & 0.59 \\
\hline & & & & ) & \\
\hline \multirow[t]{2}{*}{$\mathrm{Yb}^{3+.2} \mathrm{~F}_{5 / 2} \rightarrow \mathrm{Yb}^{3+}:{ }^{2} \mathrm{~F}_{5 / 2}$} & G & $0(97.30)$ & $1(2.56)$ & $2(0.14)$ & 27.51 \\
\hline & $\mathrm{GC}$ & $0(89.53)$ & $1(9.45)$ & $2(0.94)$ & 16.45 \\
\hline
\end{tabular}

\section{Conclusion}


In conclusion, $\mathrm{Ho} / \mathrm{Yb}$ codoped transparent oxyfluoride glasses and glass ceramics have been prepared. The large $\Delta \mathrm{T}\left(\Delta \mathrm{T}=\mathrm{T}_{\mathrm{x} 2}-\mathrm{T}_{\mathrm{g}}=140^{\circ} \mathrm{C}\right)$ of the glass suggests that it has a good thermal stability. X-ray diffraction and transmission electron microscopy demonstrated the formation of $\mathrm{NaYF}_{4}$ nanocrystals during heat treatment process. The decreased J-O intensity parameter $\Omega_{2}$ in glass ceramic confirmed the incorporation of $\mathrm{Ho}^{3+}$ into $\mathrm{NaYF}_{4}$ nanocrystals. The change of glass structure brought about by the formation of $\mathrm{NaYF}_{4}$ nanocrystals was analyzed by raman spectra. Significantly enhanced visible upconversion emission and $2.85 \mu \mathrm{m}$ emissions were achieved in glass ceramic under a $980 \mathrm{~nm}$ laser diode pumping. A broadband spectrum with a fullwidth at half-maximum close to $132 \mathrm{~nm}$ was obtained in the glass ceramic. Besides, the calculated peak emission cross section is $0.6 \times 10^{-20} \mathrm{~cm}^{2}$, suggesting the glass ceramic is a promising gain material that can be applied to broadband amplifiers in mid-infrared region. Based on emission spectra, energy transfer mechanisms in glass and glass ceramic were proposed, showing that the change of phonon energy environment around rare earth ions induced different dominant transitions in $G$ and GC. Finally, we quantitatively investigated the energy transfer process, indicating that the change of phonon energy environment has a greater impact on phonon-assisted non-resonant energy transfer process than on resonant energy transfer process.

\section{Acknowledgements}

The authors are thankful to National Natural Science Foundation of China (No. 51472225 ) , Zhejiang Provincial Natural Science Foundation of China (Nos. LY15E020009, LR14E020003, and LD18F050001), National Natural Science Foundation of China (Nos.61405182, 61370049, 51372235, 51401197 and 61605192), and Public Technical International Cooperation project of Science Technology Department of Zhejiang Province(2015c340009).

\section{References}

1. P. Zhang, B. Zhang, J. Hong, L. Zhang, J. He and Y. Hang, Optics Express, 2015, 23, 3920-3927.

2. Y. H. Tsang and A. E. El-Taher, Laser Physics Letters, 2011, 8, 818.

3. P. Zhou, X. Wang, Y. Ma, H. Lü and Z. Liu, Laser Physics, 2012, 22, $1744-$ 1751.

4. X. Tang, J. Qiu, Z. Fan, H. Wang and W. Lin, Chinese Optics Letters, 2016, 14.

5. J. Kim, J. Koo and J. H. Lee, Photonics Research, 2017, 5, 391-395.

6. L. Li, Y. Wang, D. Wang, J. Qi, F. Xia, H. Zeng and G. Chen, Chinese Optics Letters, 2016, 14.

7. $\quad$ S. D. Jackson, Optics Letters, 2004, 29, 334-336.

8. S. D. Jackson, Optics Letters, 2009, 34, 2327-2329.

9. D. Hudson, E. Magi, L. Gomes and S. D. Jackson, Journal, 2011, 47, 985-986.

10. F. Huang, X. Liu, Y. Zhang, L. Hu and D. Chen, Optics Letters, 2014, 39, 
5917-5920.

11. V. Lupei, Reference Module in Materials Science and Materials Engineering, 2016, DOI: 10.1016/b978-0-12-803581-8.03093-9, 4416-4423.

12. R. Xu, Y. Tian, L. Hu and J. Zhang, Optics Letters, 2011, 36, 1173-1175.

13. P. Kuan, X. Fan, W. Li, X. Liu, C. Yu, L. Zhang and L. Hu, Chinese Optics Letters, 2016, 14.

14. A. Lin, A. Ryasnyanskiy and J. Toulouse, Optics Letters, 2011, 36, 740-742.

15. R. Chen, Y. Tian, B. Li, X. Jing, J. Zhang, S. Xu, H. Eckert and X. Zhang, Photonics Research, 2016, 4, 214-221.

16. S. D. Jackson, Nature photonics, 2012, 6, 423-431.

17. W. Li, D. Chen, Q. Zhou and L. Hu, Chinese Optics Letters, 2016, 14.

18. X. Lu, Y. Peng, Y. Li, X. Guo, Y. Leng, Z. Sui, Y. Xu and X. Wang, Chinese Optics Letters, 2016, 14.

19. Y. Hu, R. Dou and J. Qiu, Journal of Non-Crystalline Solids, 2015, 420, 1216.

20. J. Zhao, R. Ma, X. Chen, B. Kang, X. Qiao, J. Du, X. Fan, U. Ross, C. Roiland, A. Lotnyk, L. Kienle and X. Zhang, The Journal of Physical Chemistry C, 2016, 120, 17726-17732.

21. R. Lisiecki, E. Czerska, M. Żelechower, R. Swadźba and W. RybaRomanowski, Materials \& Design, 2017, 126, 174-182.

22. W. J. Chung, K. H. Kim, B. J. Park, H. S. Seo, J. T. Ahn and Y. G. Choi, Journal of the American Ceramic Society, 2010, 93, 2952-2955.

23. T. Wei, Y. Tian, C. Tian, X. Jing, B. Li, J. Zhang and S. Xu, Ceramics International, 2016, 42, 1332-1338.

24. Z. Shan, D. Chen, Y. Yu, P. Huang, F. Weng, H. Lin and Y. Wang, Materials Research Bulletin, 2010, 45, 1017-1020.

25. G. Bai, L. Tao, K. Li, L. Hu and Y. H. Tsang, Journal of Non-Crystalline Solids, 2013, 361, 13-16.

26. P. González, J. Serra, S. Liste, S. Chiussi, B. León and M. Pérez-Amor, Journal of Non-Crystalline Solids, 2003, 320, 92-99.

27. S. Kang, Z. Fang, X. Huang, Z. Chen, D. Yang, X. Xiao, J. Qiu and G. Dong, Journal of Materials Chemistry C, 2017, 5, 4549-4556.

28. A. D. Sontakke and K. Annapurna, Journal of Applied Physics, 2012, 112, 013510.

29. P. Huang, F. Liu, D. Chen, Y. Wang and Y. Yu, physica status solidi (a), 2008, 205, 1680-1684.

30. A. E. Geissberger and F. L. Galeener, Physical Review B, 1983, 28, 32663271.

31. H. Aguiar, J. Serra, P. González and B. León, Journal of Non-Crystalline Solids, 2009, 355, 475-480.

32. J. Pan, R. Xu, Y. Tian, K. Li, L. Hu and J. Zhang, Optical Materials, 2010, 32, 1451-1455.

33. B. R. Judd, Phys. Rev., 1962, 127, 750-761.

34. G. S. Ofelt, J. Chem. Phys., 1962, 37, 511-520. 
35. C. K. Jørgensen and R. Reisfeld, Journal of the Less Common Metals, 1983, 93, 107-112.

36. B. Zhou, T. Wei, M. Cai, Y. Tian, J. Zhou, D. Deng, S. Xu and J. Zhang, Journal of Quantitative Spectroscopy and Radiative Transfer, 2014, 149, 4150.

37. Y. Wang, J. Li, Z. Zhu, Z. You, J. Xu and C. Tu, Optics Letters, 2013, 38, 3988-3990.

38. J. Li, L. Gomes and S. D. Jackson, IEEE Journal of Quantum Electronics, 2012, 48, 596-607.

39. J. He, Z. Zhou, H. Zhan, A. Zhang and A. Lin, Journal of Luminescence, 2014, 145, 507-511.

40. S. Wei, Y. Xu, S. Dai, Y. Zhou, C. Lin and P. Zhang, Physica B: Condensed Matter, 2013, 416, 64-68.

41. L. G. L. Tarelho, I. Ranieri, Phys. Rev., 1997, 56, 14344-14351.

42. D. E. McCumber, Phys Rev., 1964, 134, 299-306. 